May 2021

\title{
User Experience Desires Personalization from Academic Library Websites
}

Sarah Wilson

San Jose State University, School of Information, sarah.wilson@sjsu.edu

Follow this and additional works at: https://scholarworks.sjsu.edu/ischoolsrj

Part of the Scholarly Communication Commons, and the Scholarly Publishing Commons Acknowledgements

Thank you to all prior Student Research Journal editors who contributed to the publication as authors. You gave me to the courage to do the same. Thank you to Dr. Anthony Bernier for his eye-opening INFO 285 Youth Services course which addresses the importance of evaluation using a variety of research methods.

\section{Recommended Citation}

Wilson, S. (2021). User Experience Desires Personalization from Academic Library Websites. School of Information Student Research Journal, 11(1). https://doi.org/10.31979/2575-2499.110109 Retrieved from https://scholarworks.sjsu.edu/ischoolsrj/vol11/iss1/9

This article is brought to you by the open access Journals at SJSU ScholarWorks. It has been accepted for inclusion in School of Information Student Research Journal by an authorized administrator of SJSU ScholarWorks. For more information, please contact scholarworks@sjsu.edu. 


\section{User Experience Desires Personalization from Academic Library Websites}

\section{Keywords}

library websites, user experience, academic libraries

\section{Acknowledgements}

Thank you to all prior Student Research Journal editors who contributed to the publication as authors. You gave me to the courage to do the same. Thank you to Dr. Anthony Bernier for his eye-opening INFO 285 Youth Services course which addresses the importance of evaluation using a variety of research methods.

\section{About Author}

Sarah Wilson is a current San Jose State University MLIS student. She has a BA in Theatre from the University of California, San Diego. Sarah looks forward to a career in Youth Services upon completion of the MLIS program. 


\section{A Review of: Desmarais, B., \& Louderback, P. (2020). Planning and assessing patron experience and needs for an academic library website. Journal of Library Administration, 60(8), 966-977. https://doi.org/10.1080/01930826.2020.1820283}

Structured Abstract

Objective - To gain user feedback about the current academic library website prior to a redesign.

Design - Quantitative and qualitative survey.

Setting - A state university in a lightly-populated Oklahoma town close to the Ozarks. In fall 2019, a new content management system was chosen to house the library's online information. Before the transfer, the researchers executed this evaluation in the spring of 2020 to learn their users' priorities.

Subjects - Individuals aged 18 years and older from the university's community: (a) graduates, (b) undergraduates, (c) faculty, and (d) public-users.

Methods - The researchers used non-probability sampling. A Google Form distributed through several online means served as the research instrument. Participants remained anonymous. The survey included open-ended and non-openended questions as well as Likert scaling. Analysis was conducted on the 117 responses.

Main Results - The survey elicited stakeholders' reactions on common themes centered around the usability of the website's homepage, LibGuides, accessibility, and personalization. Respondent feedback included an appreciation for interlibrary loan, website configuration, and optional live chat. Dissatisfaction occurred in locating personal account logins and the search layout for journals and articles. Additionally, the overall website aesthetic was considered unappealing.

Conclusion - The researchers contend that academic libraries need to consider viewer needs and tailor designated sections of their website to particular users so that they are more engaging, thereby personalizing the information exchange.

Commentary

Though user experience is already a familiar topic in LIS, this study is worthy of review because of who conducted the research, how the data was obtained, and when it was gathered during the evaluation process. The principal researcher was an MLIS student intern who used freely available software to assess the website's current state before implementing any changes. Any MLIS student in a comparable position could consider using Google Forms for research, needing only a free Google account for access (Google Workspace Updates, 2016).

Academic libraries have been mindful of website user experience for the last 20 years (Gillis, 2017, p. 3). Similar to Mierzecka and Suminas (2018), this study found that easily locating the account login remains a top priority for users (p. 162). Interestingly, instruction on information retrieval, either through LibGuides or live chat, ranked higher in this study than in the earlier research conducted by Mierzecka and Suminas (2018, p. 162). Perhaps the pandemic and 
subsequent quarantine intensified the desire for direct personal interaction and curated content. The preference for increased personalization was also identified in Gillis's (2017) study, which advised libraries to avoid a homogeneous view of students and explore the benefits of adopting "user customization" (p. 5). Like Gillis, this study highlighted several differences amongst students based on their relationship with the university. Voices of a variety of graduates and undergraduates, including students who commute and those who have never set foot in the physical library, were represented. Uniquely, this study also examined non-student stakeholders in the academic community, including faculty and the general public. Unfortunately, public-users only represented $1 \%$ of the respondents, yielding little to no conclusions about this group.

The researchers acknowledged a few of their study's shortcomings. They admitted their lack of foresight to include options like "other" or "none" within the thirteen survey questions. The researchers anticipated a higher response rate and planned to conduct in-person surveys with website users at the library, especially general public visitors. However, the restrictions resulting from COVID-19 prevented this strategy. Another drawback mentioned was the choice to use nonprobability sampling, as it may not have accurately represented the full swath of users.

A limitation not acknowledged was the adoption of only one research method - a survey. Gillis (2017) conducted interviews, issued predesigned tests, and utilized Blackboard Collaborate to monitor how users interacted with a library's homepage (p.7). Employing methods similar to Gillis's by using other free research tools in tandem with Google Forms could produce further insight. For example, participants could share their screens and record videos of their web usage via programs like Zoom. Observing how users actually interact with library web pages may reveal things not reported within a survey. Additionally, implementing focus groups through Zoom would allow for discussion, yielding opportunities for feedback that individuals might not generate on their own. Lastly, Bedi and Webb (2017) used a method called photo-elicitation, whereby images help to promote discourse. Photo-elicitation can be used two different ways: Researchers can display visuals of their topic to spur dialogue with participants, or users can present their own images to recall their personal impressions. Collected screenshots representing different areas of the website could be taken by users and/or researchers then uploaded into a Google Slides presentation to facilitate evaluation.

The study also had a limited categorization of students and other users. Asking participants to self-identify among a broader range of options, without disclosing direct personal information, might lead to further discoveries. Limas's (2020) study of undergraduates noticed a multitude of distinctions and crossover among student demographics and interests. If personalization is something researchers want to incorporate, they need to know more detail about their user groups to address their needs.

The researchers concluded that personalization was key to improving an academic library website. However, no suggestions are offered, other than the development of more LibGuides. With the advent of COVID-19 stifling face-toface contact, one possible way to foster connection between a library and its users 
is targeted video content. Creative videos may be an effective means of communicating with different audiences while also helping users familiarize themselves with the site's features and navigation. For instance, Limas (2020) describes undergraduate students filming videos of their campus and uploading them to YouTube as an informal marketing tool (p. 27). If libraries add personalized and engaging video content to their websites, they may bridge the gap between information professionals and users. Libraries could even collaborate with their users to create and evaluate the content.

This study was published at a crucial time. Though COVID-19's long-term societal effects remain unclear, our reliance on the internet for connection and information retrieval is evident. Many libraries closed their physical doors during the pandemic, leaving digital outreach as their primary communication channel. Information professionals might ask themselves, are the services outlined on their website clearly understood by the user? It is commendable that this study sought to answer that question with user feedback analysis, establishing a benchmark before undergoing a redesign. This examination was performed at an academic library, but other types of libraries could consider the study's methods, evaluation techniques, and results to improve the usability and appeal of their own websites. They could pinpoint users' needs, enhancing their experience while also saving time and resources.

\section{References}

Bedi, S., \& Webb, J. (2017). Through the students' lens: Photographic methods for research in library spaces. Evidence Based Library and Information Practice, 12(2), 15-35. https://doi.org/10.18438/B8FH33

Gillis, R. (2017). "Watch your language!": Word choice in library website usability. Partnership, 12(1). 1-27. https://doi.org/10.21083/partnership.v12i1.3918

Google Workspace Updates. (2016, February 10). New Google Forms now the default option, with improvements to add-ons, script editing, and more. https://workspaceupdates.googleblog.com/2016/02/new-google-formsnow-defaultoption.html?utm_source=zapier.com\&utm_medium=referral\&utm_campa ign=zapier

Limas, B. (2020). The evolving information needs and behaviors of undergraduates. School of Information Student Research Journal, 10(2), 21-30. https://doi.org/10.31979/2575-2499.100203

Mierzecka, A., \& Suminas, A. (2018). Academic library website functions in the context of users' information needs. Journal of Librarianship and Information Science, 50(2), 157-167. https://doi.org/10.1177/0961000616664401 